\title{
MODIFICATION OF STANDARDIZED AGILITY 505 TEST BY USING MODERN TECHNOLOGY
}

\author{
Aleksandar Živković, \\ Ivan Ćuk, \\ Srdjan Marković*
}

\section{Singidunum University,} Belgrade, Serbia

\begin{abstract}
:
The upright body position, the movements of the body segments, and any human activity require a certain level of motor skills. The quality of motor skills and the pace of their development (under the influence of training) directly affect human daily activities, as well as human health status. In sports, they are directly related to the result, whereas, in team sports, speed and agility are perhaps the most important ones. However, finding an acceptable definition of agility is most likely the result of the influence of various factors from different disciplines of sports science, which affect the manifestation of agility. The most accepted definition of agility is the rapid movement of the whole body with a change in speed or direction of movement in response to a certain stimulus, whereas examples of agility assessment protocols are 505, T-test, Step aside, Zigzag test. Of all the agility tests mentioned, the 505 test is the most commonly used for testing both junior and elite athletes. The test itself has the most possibilities for modification since only small corrections can take into account the specifics of the sports. In sports, there is an increasing tendency to save athletes from long testing procedures and to test as many motor skills as possible in the shortest possible time, thus the new tests need to be as effective as possible. Therefore, this paper aims to propose a future modification of the 505 test to test other motor skills in addition to agility by using modern technology.
\end{abstract}

Keywords:

505 test, agility, speed, evaluation, validity.

\section{INTRODUCTION}

The upright body position, the movements of the body segments, and any human activity require a certain level of motor skills. They represent the human ability to establish movement and solve motor actions that are set as a task or need [1]. Motor abilities combine biochemical and functional processes, as well as psychological characteristics that are limited by the human neuromuscular system [2]. As a result, motor skills represent a wide research field. The quality of motor skills and the pace of their development (under the influence of training) directly affect human daily activities, as well as their health status. In contrast, in sports, they are directly related to achieving top results. Analytically, motor skills are described as abilities of strength, speed, power, endurance, coordination, flexibility, and agility [3].
Correspondence:

Srdjan Marković

e-mail:

smarkovic@singidunum.ac.rs 
There is no consent in scientific publications about the definition of agility. Agility is traditionally defined as the ability to quickly change direction [4], but also the ability to change direction quickly and accurately [5]. In some publications, the authors have included in the definition a change of movement direction of the whole body, as well as rapid movements and a change of movement direction of the extremities [6].

Therefore, agility is not easy to define, since it represents a synthesis of almost all physical abilities that an athlete possesses. In accordance, agility is manifested in several forms, ie in (1) horizontal changes in the direction of the whole body, such as body maneuvers or avoiding the opponent; (2) vertical changes in the direction of the whole body, such as jumping and skipping, and (3) rapid movements of certain parts of the body that control props in sports, such as tennis, hockey, squash [7]... In the recent decades a more comprehensive classification of agility appears, as well as addressing the multiple factors included in the classification of agility. In more detail, they state that there are two main components of agility - (1) change of direction speed (CODS) and (2) perceptual and decision-making factors [8]. Within these two main components, there are subcomponents, shown in Figure 1.

A critical review of the literature has proposed the following definition of agility: "... rapid movement of the whole body with a change of direction speed in response to a stimulus" $[9,10]$.

Externally, movements with a change of direction are characterized by acceleration of movement, deceleration of movement, and different degrees of change of direction. Since the movement is performed at the maximum possible speed, the most common features in the tasks for assessing agility (tests) are fast movements from the place (start), acceleration, deceleration to relative stop, and later changes of direction and acceleration after changes of direction. This sequence of changing movement characteristics is performed at least once (as in test 505, for example) or, depending on the task, repeated three to ten times (sometimes more than 10 times). From the aspect of motor abilities, the characteristics of strength (maximum strength and rate of force development) are important for the successful movement at the start, strength is important for acceleration and deceleration of movement, and coordination is important for the change of direction and movement technique. Success in agility tasks depends on different participation of strength and power, as motor abilities in changed movement conditions, ie it depends on coordination as a motor ability.

On the other end of the definition, in which agility is seen as a complex ability, suggest that it consists of: a) perceptual and decision factors - observation, prediction, and assessment of the situation and b) speed of change of direction - movement technique, speed, leg muscle characteristics and anthropometric characteristics [8]. In this determination, it can be noticed that for the successful manifestation of agility, in addition to perceptual factors, the characteristics of the leg muscles and morphological characteristics are also important. Based on the previously reported definitions, one can see the extreme complexity of agility as a motor ability because, in different scope and intensity, it includes the characteristics of morphological and psychological characteristics and motor abilities. The complexity of agility is reflected in the open character of motor skills [11], ie in the rapid change of direction in response to a stimulus [9].

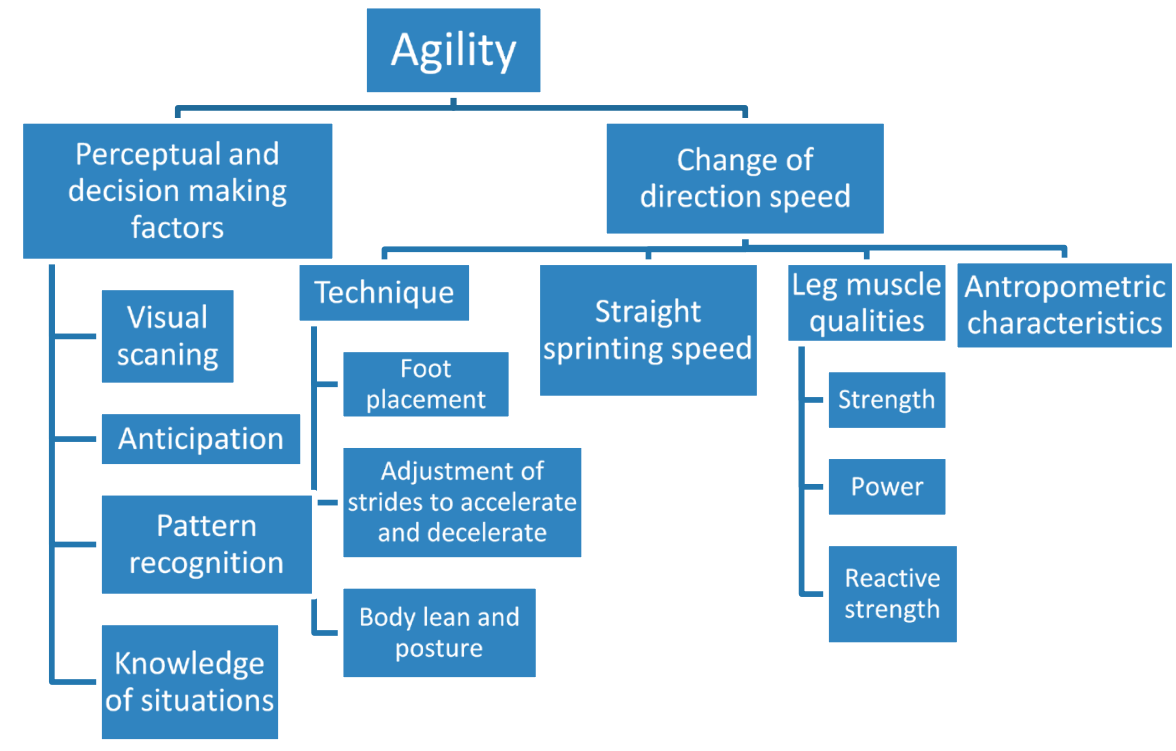

Figure 1 - Components of agility $[8,9,10]$ 
The assessment of agility is performed by various tests that contain acceleration, deceleration, and change of direction, and test protocols involve more or less specific patterns of movement (complexity of movement) concerning the movement characteristics in certain sports and disciplines such as football, basketball, handball, volleyball, tennis, etc. Examples of agility assessment protocols include 505 test, T-test, Step aside, Zigzag test, etc. [12]. It is clear that these tests contain the speed of running and changing direction, but the result obtained by measuring these tests is calculated as a result that shows us the agility of the subjects, although in all these cases we have given distances $5,10,15,20$ or 30 meters. The distance that the participant should run in the shortest possible time is different, primarily due to the sport in which the participant is engaged or his age.

Of all the agility tests mentioned, 505 test is the most commonly used in agility tests in both the junior and senior categories [7]. It is very efficient since the width of one athletic track and the length of $25 \mathrm{~m}$ are enough for measurement. The test itself has the most possibilities for modification since only small corrections can take into account the specifics of the sports [13].

In this regard, this paper aims to propose a future modification of the 505 test to test other motor skills in addition to agility by using modern technology.

\section{METHODS}

For the purposes of this study, a bibliographicdescriptive method was used. Literature search was conducted with following services: PubMed, Google, Google Scholar and Kobson. The keywords for searching the appropriate literature were: speed, agility, 505 agility test, running speed, human motor skills.

\section{RESULTS AND DISCUSION}

The possibilities for modification of the 505 test are numerous. This test consists of parts that can be evaluated and that the specificity entered is crucial for research in a particular sport [14]. Viewed from the angle of change in the performance of participants after several consecutive repetitions of the same test, it can be determined how the measured ability changes [15]. In this regard, the speed at $5 \mathrm{~m}$ or $10 \mathrm{~m}$, time to change direction, or response to an external stimulus may be introduced. The first part of the standard 505 test $(10 \mathrm{~m})$, which represents the distance for increasing speed, and which is not measured, provides a possibility for modification. For example, measuring the speed at $10 \mathrm{~m}$, as well as at the first $5 \mathrm{~m}$ can be introduced. As a result, this modification would provide two results in the same attempt (test), namely the results of speed at $5 \mathrm{~m}$ and $10 \mathrm{~m}$, while measuring agility.

Therefore, measuring two abilities in one test will reduce the testing time and consequently the workload of the participants (e.g. elite athletes). Such test should require further evaluation, as well as a new name (such as modified 505 test i.e. M505 test).

The following instruments would be used for testing: computerized photocell system, Martin anthropometer, In body 720 bioimpedance. On the first day, morphological characteristics would be tested, as well as speed testing at $10 \mathrm{~m}$ with a checkpoint time at $5 \mathrm{~m}$ and a standard 505 agility test results. The morphological characteristics that would be measured are body height, body weight, as well as body composition - muscle tissue, adipose tissue, and the ratio of mass to body height (BMI).

\subsection{SPRINT TESTS}

Assessment of the paticipants' speed would be performed by a 10-meter running test, within which the variables time at $5 \mathrm{~m}$ and $10 \mathrm{~m}$ would be monitored. In this test, the participants would have to run a 10-meterlong track by moving from a high start, in the shortest possible time. In addition to measuring the running time at $10 \mathrm{~m}$, this test would also measure the running time needed to cross the first 5 meters. Measurement of running speed at $5 \mathrm{~m}$ and $10 \mathrm{~m}$, respectively, would be performed using a computerized system of photocells. Participants would begin the task at their convenience. Before the measurement, the subjects would have one pretest attempt, followed by two test attempts.

\subsection{TEST}

Participants would have the task to cross the distance between the markers $15 \mathrm{~m}$ apart in the shortest possible time. A computerized photocell system for measuring time will be placed at the tenth meter (Figure 2). Subjects will try to achieve maximum acceleration from the start line to the photocell $(10 \mathrm{~m})$, then stop behind the line of the second marker, change direction for 180 degrees, and sprint again to the finish line $(5 \mathrm{~m})$. The total distance in this task is 20 meters ( $10 \mathrm{~m}$ run-up, and $2 \times 5 \mathrm{~m}$ measuring distance). 


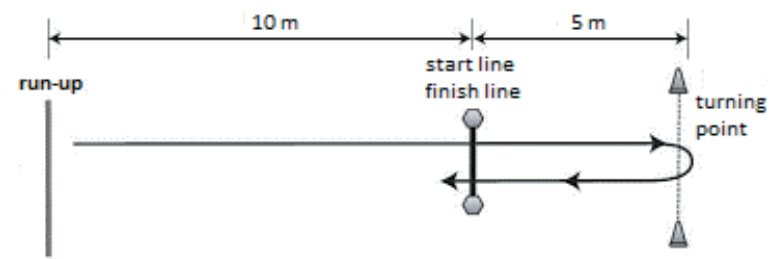

Figure 2. Movement of subjects during the performance of the agility assessment test in 505 test

Before measuring, the participants should have one pretest attempt, followed by two test attempts turning on the same leg. The second day of testing would take place after three days of rest, with a modified 505 test. These results would be taken to determine the validity of the test.

\subsection{MODIFIED 505 TEST}

Participants would have the task to cross the distance between the markers $15 \mathrm{~m}$ apart in the shortest possible time. A computerized photocell system for timing will be installed at the starting line, at the 5 th meter, and at the 10th meter. Markers are also placed 15 meters from the start. Participants would move from the starting line after the sign that the system is ready and based on their own decision when to start the test. Participants would try to run their maximum from the start line, and then stop behind the line of the second marker, turn 180 degrees, and sprint again, maximally accelerating to the finish line $(5 \mathrm{~m})$.

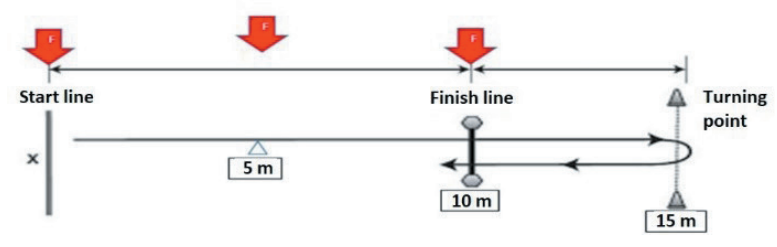

Figure 3. Movement of subjects in the modified M505 test with photocell positions (red arrows F)
The total distance in this task would be 20 meters. The time is recorded with photocells in the first $5 \mathrm{~m}$ at $10 \mathrm{~m}$ and then, as in the standard 505 test, the time of the last $5 \mathrm{~m}$, changing the direction by 180 degrees and returning to the second marker. Each participant would repeat the test three times.

\section{CONCLUSION}

For decades, testing has been a basic means of controlling the physical status of athletes. Over time, the tests were changed and evaluated following the needs or new technologies that both improved the quality and facilitated their performance. Testing that has been done with teams of athletes for several days has now been reduced to a couple of hours. It is expected that by evaluating this modified 505 test, a new test will emerge that will provide the results of speed and agility in only one measurement, thus shortening the testing time and strain on the athletes. The use-value of this test is reflected in the fact that in most sports games, basketball, football, handball, volleyball, distances of $5 \mathrm{~m}$ and $10 \mathrm{~m}$ are incorporated, which are important and the basis of movement in the game. In all mentioned sports except football, these are also the dominant distances.

The speed at these distances, as well as agility could be tested simultaneously in the modified 505 test. As a result, in some critical periods of the competition, the modified 505 test could provide answers to the coaches about these abilities that directly affect the team's game.

\section{REFERENCES}

[1] J. Malacko and I. Radjo, Tehnologija sporta i sportskog treninga, Sarajevo: Univerzitet u Sarajevu, Fakultet sporta i tjelesnog odgoja, 2004.

[2] V. M. Zaciorski, Fizička svojstva sportiste, Beograd: JZFK i FFK, 1969.

[3] T. Bompa and C. Buzzichelli, Periodization: Theory and Methodology of Training, Champaign, IL: Human Kinetics, 2019.

[4] J. Bloomfield, T. R. Ackland and B. C. Elliot, Applied anatomy and biomechanics in sport, Melbourne, VIC: Blackwell Scientific, 1994.

[5] H. Barrow and R. McGee, A practical approach to measurement in physical education, Philadelphia, PA: Lea \& Febiger, 1971.

[6] J. Draper and M. Lancaster, “The 505 test: A test for agility in the horizontal plane," Australian Journal of Science and Medicine in Sport, vol. 17, no. 1, pp. 15-18, 1985. 
[7] M. Verstagen and B. Marsello, "Agility and coordination," in High performance sports conditioning, Champaign, IL, Human Kinetics, 2001, pp. 139-165.

[8] W. Young, R. James and I. Montgomery, "Is muscle power related to running speed with changes of direction?," Journal of Sports Medicine and Physical Fitness, vol. 42, p. 282-288, 2002.

[9] J. M. Sheppard and W. B. Young, "Agility literature review: Classification, training and testing," Journal of Sport Sciences, vol. 24, no. 9, pp. 919- 932, 2006.

[10] W. Young and D. Farrow, "A review of agility: practical application for strength and conditioning," Strength and Conditioning Journal, vol. 28, no. 5, pp. 24-29, 2006.

[11] I. Jeffreys, "Motor Learning-Applications for Agility, Part 1," Strength and Conditioning Journal, vol. 28, no. 5, p. 72-76, 2006.

[12] L. Ellis, P. Gastin, S. Lawrence, B. Savage, A. Buckeridge, A. Stapff, D. Tumilty, A. Quinn, S. Woolford and W. Young, "Protocols for the physiological assessment of team sports players.," in Physiological tests for elite athletes, Champaign, IL, Human Kinetics, 2000, pp. 128-144.

[13] T. Dos'Santos, A. McBurnie, C. Thomas, P. Comfort and P. A. Jones, "Biomechanical Determinants of the Modified and Traditional 505 Change of Direction Speed Test," Journal of Strength and Conditioning Research, vol. 34, no. 5, p. 1285-1296, 2020.

[14] R. Blagrove, C. Bishop, G. Howatson and P. Hayes, "Inter-limb strength asymmetry in adolescent distance runners: Test-retest reliability and relationships with performance and running economy," Journal of Sports Sciences, vol. 39, no. 3, pp. 312-321, 2021.

[15] A. T. Scanlan, M. C. Madueno, J. H. Guy, K. Giamarelos, T. Spiteri and V. J. Dalbo, "Measuring Decrement in Change-of-Direction Speed Across Repeated Sprints in Basketball: Novel vs. Traditional Approaches," Journal of strength and conditioning research, vol. 35, no. 3, pp. 841-845, 2021. 